\title{
Solving a Demand-Supply Mismatch by Enabling a Value Chain Orientation
}

\author{
Rajesh Shankar Priya
}

Teesside University Business School, Middlesbrough TS1 3BX, United Kingdom

\begin{abstract}
Supply-Demand mismatch is a continuous challenge among suppliers creating poor customer service levels and often leading to higher costs to the entire supply chain, to meet the demands of the customer. This paper will highlight demand-supply mismatch issues between a steel supplier having supply issues with one of its premier automobile customers due to difficulties in forecasting the appropriate demand from the customer. The outcome of the original research was developing a framework for an integrated planning process that overlooks the entire demand planning and management of the customer, in addition to emphasizing the application of demand profiling that enabled to build a novel future state inventory model. In the context of the work published here, an enabler and inhibitor analysis was conducted, that studies the structure and processes within and between firms, to identify any business implications that may affect the demand-supply mismatch.
\end{abstract}

KEYWORDS: Supply Chain, value chain, demand, supply, collaboration, performance, management support https://doi.org/10.29294/IJASE.7.4.2021.1943-1949 $\quad$ (c) 2021 Mahendrapublications.com, All rights reserved

\section{INTRODUCTION}

Automotive suppliers often place top emphasis in matching supply and demand to satisfy the customer. However, most of them invariably struggle to solve the supply and demand challenge, creating a huge decline in customer service levels and ultimately losing market share and economic benefits, due to additional costs in meeting customer demands [1]. Even in the 1960's, when companies mainly focussed on solving process engineering challenges, the demand-supply mismatch was a strenuous issue for managers [2]. It was predicted that there will be a long, continuous trade-off between customer requirement and satisfaction. However, customer satisfaction eventually got prioritized in subsequent terms, on-par with cost and quality in manufacturing strategies around the 1990's [3]. Up until the 1990's, cost and quality were the main pillars of manufacturing strategy and delivery performance was never an important attribute. However, it is claimed that "The global competition is not only based on product quality or cost but in combination with performance of the delivery" [4]. Any supply chain management concept that enhances productivity is significantly dependent on strategic decisions taken along the value chain, with firm collaboration between companies that include joint planning, joint forecasting and managing inventory dynamics in a collaborative manner [5]. However, most of the companies still plan independently within their business units with no visibility in their own downstream processes. Despite numerous efforts taken by suppliers to forecast demand that can guarantee a stellar level of customer service, they recurrently face obstacles in the form of demand forecasting, planning and management [6], the prime reason being volatility and the variability of demand that occurs within the entire value chain [7] While on one hand, the customer still shares information to the suppliers on demand and on the other, suppliers forecast the demand using forecasting tools, there is still a massive gap in demand and supply due to the accuracy of demand [8].

\section{Joint Planning}

Any level of internal planning involves complex, multidisciplinary teams at various levels of the organization, using different collaboration techniques and practices to drive a common objective. This can be difficult considering the often-reactionary nature of businesses, despite having a common management structure. In order to implement a joint planning exercise with two different management structures across the value chain, it is pivotal to study the structures and processes with and between the different functions and members. It is assumed by default that different management systems with different organizational structures use different mechanisms to measure performance, information sharing and customer relationship behaviour. In that regard, the objective of this study was to 
identify the key enablers and inhibitors between these two businesses and if there any implications that affect the business performance that could eventually cause the demand-supply mismatch. The results published here demonstrate the enablers and barriers for joint planning that exist within companies to facilitate such an exercise that can potentially minimize the supply-demand mismatch.

\section{Context of the Study}

In consideration with the context of the study: Organizational Structure, Internal Relationship Behaviour, Customer Relationship Behaviour, Top Management Support, Information Sharing and Performance Measure Systems of the two companies were chosen to study based on the framework [9]. The response rate was 91\% from supplier and $66 \%$ from the OEM. The roles of the people who participated in this study are listed in Table 1.

Table.1

\begin{tabular}{|l|l|l|}
\hline \multicolumn{2}{|l|}{ Department } & \multicolumn{1}{|c|}{ Supplier } \\
\hline $\begin{array}{l}\text { Supply } \\
\text { Chain }\end{array}$ & Director of SC & $\begin{array}{l}\text { Head of Supply } \\
\text { chain }\end{array}$ \\
\hline $\begin{array}{l}\text { Customer } \\
\text { Service }\end{array}$ & $\begin{array}{l}\text { Customer } \\
\text { service } \\
\text { managers }\end{array}$ & $\begin{array}{l}\text { Customer } \\
\text { service } \\
\text { managers }\end{array}$ \\
\hline Demand & $\begin{array}{l}\text { Demand } \\
\text { Planners }\end{array}$ & $\begin{array}{l}\text { Demand } \\
\text { Planners }\end{array}$ \\
\hline Planning & $\begin{array}{l}\text { Process lead } \\
\text { teams }\end{array}$ & $\begin{array}{l}\text { Process Lead } \\
\text { teams }\end{array}$ \\
\hline
\end{tabular}

\section{Organization Structure}

On analyzing the organization structure of the companies particularly on the cross-functional knowledge exchange and inter-departmental activities taking place within the company on these key attributes:

1) The control operations for the core business processes (Plan, Source, Make, Delivery and Sales) of the SC director.

2) Process owners for each of the core business processes

3) Cross-functional knowledge and skills within the company

4) Department organized according to the core business processes Interdepartmental activities
It is evident according to Figure 1 that the Supply Chain director at the supplier's end has more control in the business processes than the OEM's management. However, it is also obvious that companies are identical on process ownership and both companies are driven by processes. In the cross-functional knowledge and skills required to manage the core business processes, the supplier exhibits a slight improvement over its customer. However, on analyzing the pattern of this entire block, both the companies can be benefitted on any changes made on a process level as they both exhibit a strong culture driven by processes.

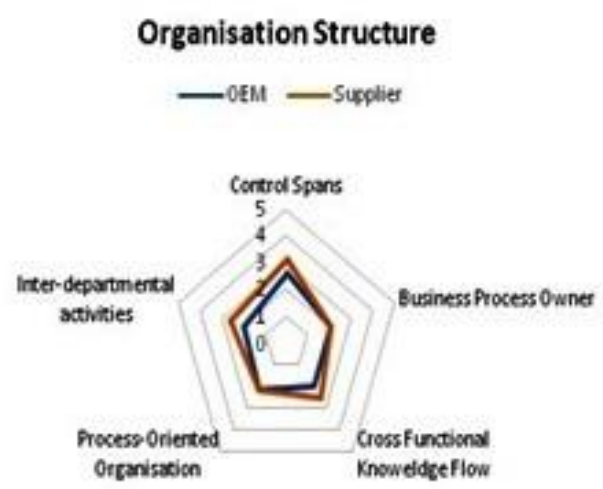

Figure 1: Organizational Structure

\section{Internal Relationship Behaviour}

On investigating, the internal activities that facilitate the process of cross-functional relationship based on the attributes listed below:

1) Employee involvement in cross-functional activities

2) Current level of mutual understanding in terms of business processes

3) Joint planning and problem-solving practices

The evidence provided in Figure 2, highlights the pattern of cross-functional teamwork with most functional departments having a positive trend to plan and solve problems together in the core business processes. They in addition, also exhibit a good understanding of each other's business processes. Overall, the internal relationship behaviour of both the companies highlights professional behaviour and willingness to jointly plan and solve problems.

\section{Customer Relationship Behaviour}

As joint planning require strong dedicated customer relational behaviour. It is crucial to 
identify the behaviour patterns and the current indicators to measure if any positive trends can be found. The customer relationship behaviour was measured with the metrics of goal and cost sharing practices along with the joint problem-solving and planning practices between the two companies. The attributes that were measured are as follows:

1) Goal Sharing Practices

2) Cost Sharing Practices

3) Joint Problem-Solving Practices

4) Joint Planning Practices

5) Profit Sharing Practices

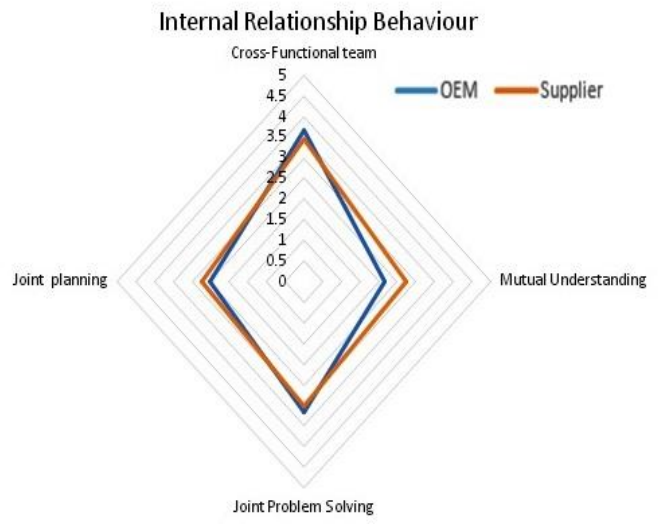

Figure 2: Internal Relationship Behaviour

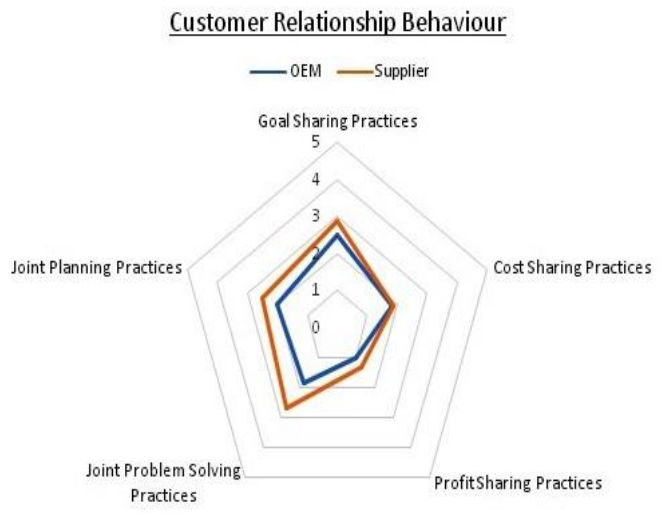

Figure 3: Customer Relationship Behaviour

As illustrated in Figure 3, it is evident that the supplier's customer relationship behaviour strategy and practices are better than OEM's practices. The companies already involve in some cost sharing practices, but it is not evident if the cost is shared with any customer or with most of the key customers. It is also evident that the supplier is keen to share its future goals to the supplier with more commitment in joint-planning and joint-problem solving practices.

\section{Top Management Support}

This the most interesting piece of evidence gathered during this research that determines the barriers of joint planning in an end to end value chain. The key attributes that were used to check the management support were:

1) Management listening to issues on core supply chain issues

2) Management participation in supply chain meetings

3) Investment in HR and other resources by Management

4) Level of strategic involvement in supply chain management

5) Awareness of needs and capability by the top management

Figure 4: Top Management Support.

Top Management Support
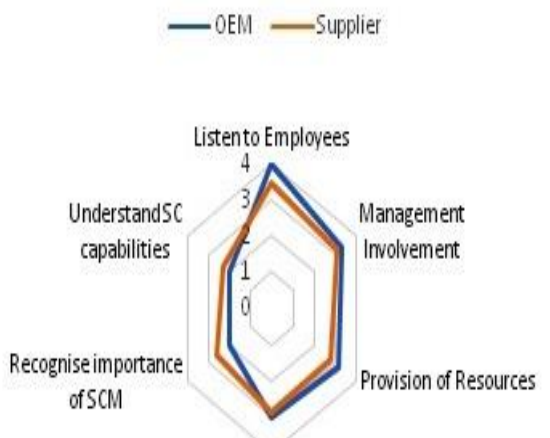

Provision of finance

Based on the results highlighted in Figure 4, it is evident that the OEM's top management is keen to listen to its employees and have a slightly positive trend in provision of HR and other capital investments. However, it was surprising to note that top managers in both companies have lesser supply chain capabilities and highlighted minimal strategic involvement in building relationship with suppliers. Whilst the top management showed little interest in building key relationship, the subsequent teams working under the management exhibited minimal interest in joint planning activities, despite having the necessary skills and processes to build stronger relationships. The top management was more focused on management involvement on an operational platform but not proactive to build key relationships. It was also evident that the top-management participated in regular meetings. However, they infrequently read the reports generated by the technical teams, derecognising the importance of supply chain management. 


\section{Information Sharing}

In this section, it was essential to evaluate if the information sharing was accurate, enough and in a timely manner. The metrics used to analyze the information sharing aspect of the collaboration are listed below:

1) Sharing relevant information within and between teams

2) Sharing accurate information within and between teams

3) Sharing enough information within and between teams

4) Timely sharing of information within and between teams

5) Knowledge to use the shared information among the teams.

The Figure 5 highlights that there is a conservable gap between companies on the aspect of sharing relevant information. The information available to the supply chain department seems to be relevant to the management of the material flow. However, there are no signs that the accuracy of the information in terms of the material flow despite the information being shared in timely manner. Both the companies have identical pattern in displaying lower level of knowledge to use the available information.

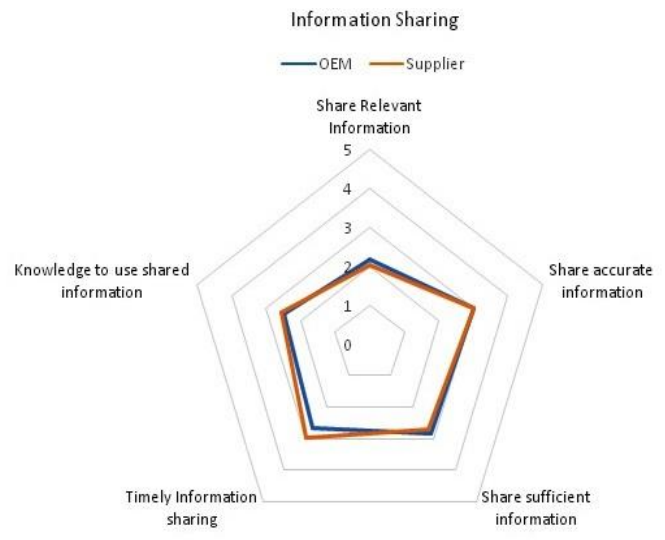

Figure 5: Information Sharing

\section{Business Performance Measurement Systems}

The core links between the strategic objectives and performance targets were reviewed in this analysis. It was examined if performance measures were used to optimize processes across the functions. The key metrics used to identify the measurement systems:

1) Strategic Objectives
2) Timely Reporting
3) Shared Incentives and rewards
4) Shared performance metrics.

In Figure 6, it is evident that the performance targets at both companies, at different organization levels are slightly linked to the overall business objectives of the company and in most cases, reviewed and reported at agreed intervals set by the management.

\section{Summary of the Enablers and Barriers}

The key Enablers and Barriers identified during this analysis are listed in Table 2 and Table 3 respectively.

Table 2: Enablers of Joint Planning

\begin{tabular}{|c|l|l|}
\hline No & Enabler & \multicolumn{1}{c|}{ Explanation } \\
\hline 1 & $\begin{array}{l}\text { Cross } \\
\text { functional } \\
\text { team }\end{array}$ & $\begin{array}{l}\text { Both companies exhibit } \\
\text { good internal planning } \\
\text { and problem-solving } \\
\text { capabilities. }\end{array}$ \\
\hline 2 & $\begin{array}{l}\text { Feedback } \\
\text { Mechanism }\end{array}$ & $\begin{array}{l}\text { The top management is } \\
\text { keen to listen and are } \\
\text { actively involved with } \\
\text { employees. }\end{array}$ \\
\hline 3 & $\begin{array}{l}\text { Reporting } \\
\text { Mechanism }\end{array}$ & $\begin{array}{l}\text { Strategy } \\
\text { reporting mechanism in } \\
\text { place and the supplier is } \\
\text { keen in enhancing this } \\
\text { method. }\end{array}$ \\
\hline
\end{tabular}

Based on the research results, it is conspicuous that despite both companies being driven by consolidated processes, fail to share the vital demand and supply planning parameters that is required to minimize the demand-supply mismatch. It is also pivotal to recognize the top management support can facilitate joint planning activities, if the importance of the supply chain management is recognized. 


\section{Future State Collaboration}

The overall objective is to enable the companies to move towards a value-chain orientation that synchronizes the entire planning between the twofirms. In order to shift the local planning procedure to a systematic joint-planning procedure, system optimization techniques are recommended that can eventually minimize the inventory and lead-time. Joint-planning exercises are a key performance measure towards achieving the goal of a highly productive supply chain. Despite the daily, monthly and quarterly review meetings that take place with the customer support team of companies, there is a strong focus on execution of deliverables, rather than planning for the future. The KPI's are standardized across all the meetings for delivery, quality and for any innovation practices set for the future. Based on the E\&I analysis, a future state roadmap is collaboration is recommended as shown in Figure.7.

In this road map, the initial steps are taken to redesign the current meeting setups that are related from execution to planning. The next phase is to establish communication channel that transmit the list of actions to be solved based on priority from a joint planning committee that oversees planning operations. The risks and mitigation strategy along with the resource requirements is communicated by the committee to the top management in a timely manner. The next phase is the anticipation phase where there are measures, based on anticipation of deviation of demand or any major incidents that could disrupt the performance of the Supply Chain.

\section{Barriers of Inter-Firm Planning}

To construct Integrated Inter-Firm planning process architecture, two potential barriers are identified:

\section{1) IT / ERP system Integration \\ 2) Differentiation of Demand}

\section{IT / ERP System Integration}

As companies have different internal processes that work in eliminating inventory buffers within several internal business units. A lot of real-time information is shared with in these units and a majority of the companies use ERP systems [10] However, on integrating with external platforms, there is a necessity to involve multiple-levels of safety measures in real-time and a consolidated system integration platform between two IT systems. The current state of art inter-firm planning is based on data from independent ERP systems with add on tool (shared), that can be used by two companies, independently. However, for future research, it is necessary to identify the critical factors for successful cyber-physical interfacing between two companies based on Industry 4.0 principles. According to (Khaparde 2012), critical factors for a successful implementation are:

1) Clear understanding of strategic goals

2) Identify multi-site issues

3) Commitment by top management.

4) Project Management

Table 3: Barriers of Joint Planning

\begin{tabular}{|c|c|c|}
\hline No & Inhibitor & Explanation \\
\hline 1 & $\begin{array}{l}\text { Joint } \\
\text { Planning } \\
\text { Activities }\end{array}$ & $\begin{array}{l}\text { Despite highlighting a } \\
\text { positive trend in } \\
\text { internal planning, there } \\
\text { is a definite need for } \\
\text { joint planning and } \\
\text { problem-solving } \\
\text { practices between two } \\
\text { companies }\end{array}$ \\
\hline 2 & $\begin{array}{l}\text { Sharing } \\
\text { Information }\end{array}$ & $\begin{array}{l}\text { Both companies are in } \\
\text { the need to develop new } \\
\text { mechanisms to share } \\
\text { relevant, accurate and } \\
\text { enough information in a } \\
\text { timely manner }\end{array}$ \\
\hline 3 & $\begin{array}{l}\text { Provision of } \\
\text { Resources }\end{array}$ & $\begin{array}{l}\text { The top management of } \\
\text { both the companies are } \\
\text { currently reluctant to } \\
\text { provide the necessary } \\
\text { financial resources, as } \\
\text { they do not recognize } \\
\text { the important of Supply } \\
\text { Chain Management } \\
\text { activities }\end{array}$ \\
\hline 4 & $\begin{array}{l}\text { Change } \\
\text { Management }\end{array}$ & $\begin{array}{l}\text { There is a negative trend } \\
\text { on both companies in } \\
\text { implementing any } \\
\text { change or adjusting the } \\
\text { needs of the customer. }\end{array}$ \\
\hline
\end{tabular}

\section{Differentiation of Demand}

The issue concerning overestimation of demand from typical sales functions occur very frequently 
in companies, ensuring stocks is available to fulfill orders. It is therefore critical also to integrate sales teams in demand calculation.

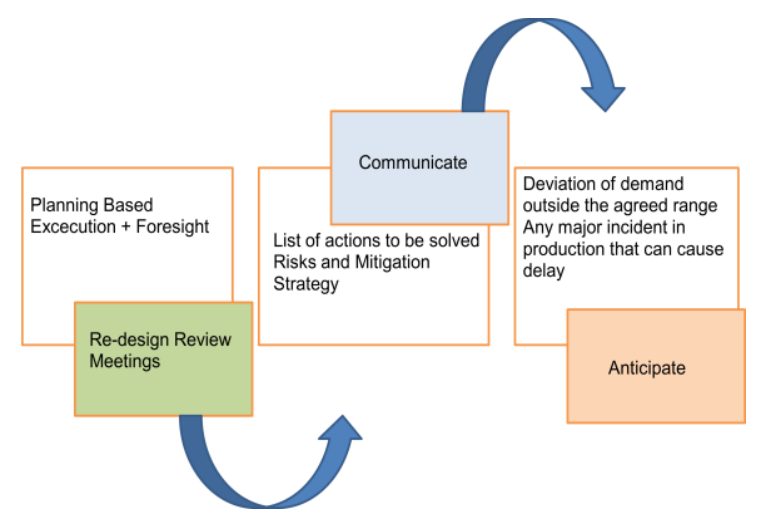

Figure 7: Future State Collaboration.

\section{CONCLUSION}

The strategic element of any Sales and Operation Planning (S\&OP) is managing customer and defining how customer groups are served to ensure that supply capacity is available to meet any demand [11]. However, working with customers in an integrated platform is a key element of the planning process, to identifying and discovering the real customer needs for driving profitable service solutions. An integrated interfirm planning process between companies can be responsible to provide an accurate demand signal to the rest of the SC, ensuring minimal write-offs and delays in the SC. However, companies decentralize the planning system, citing to difficulties in implementation of an integrated planning process [12]. With an integrated interfirm planning process, visibility of the SC becomes higher allowing the demand fluctuations to be relayed much quicker to the upstream, minimizing the bullwhip effect. An integrated, inter-firm planning process narrows the gap by offering a tailored supply chain strategy through demand profiling. Despite claims, that realization of such an integrated platform where two companies integrate their planning process in to single set of information flow is highly impossible [13], companies like IKEA, Dell and ZARA have transitioned successfully from a decentralized planning to an integrated planning strategy with in their internal supply chain in the last decade [14] However, beyond the E\&I analysis addressed in this work, it is also vital to:

1) Examine the current stage of planning process, delivery strategies, performance levels and studying the demand, supply and inventory process.
2) Develop inventory models that highlight potential business benefits for the companies involved based on demand profiling.

3) Assess planning and collaboration issues through a maturity assessment tool.

4) Propose a pragmatic future state design in the form of a big picture map enabling the companies to exercise better planning procedures [15].

\section{REFERENCES}

[1] Jasti, N.V.K. and Kodali, R., 2015. A critical review of lean supply chain management frameworks: proposed frame work. Production Planning \& Control, 26(13) 1051-1068

[2] Skinner, W., 1986. The Productivity Paradox. Harvard Business Review, 64(1) 17-21.

[3] Leong, G.K. and Ward, P.T., 1995. The six Ps of manufacturing strategy. International Journal of Operations \& Production Management. 13(2) 99-115.

[4] Beamon, B.M., 1999. Measuring supply chain performance. International journal of operations and production management 19(3) 275-292

[5] Houlihan, J.B., 1988. International supply chains: a new approach. Management Decision, 26 (3) 13-19

[6] Johnson, Mark \& Stevens, Graham. (2016). Integrating the Supply Chain... 25 years on. International Journal of Physical Distribution \& Logistics Management. 46. 10.1108/IJPDLM-07-2015-0175.

[7] Brinch, M. and Stentoft, J., 2017. Digital Supply Chain: Still More "Wannabe" Than Practice. DILF Orientering, 54(2), 22-28.

[8] Syntetos, A.A., Babai, Z., Boylan, J.E., Kolassa, S. and Nikolopoulos, K., 2016. Supply chain forecasting: Theory, practice, their gap and the future. European Journal of Operational Research, 252(1) 1-26.

[9] Skipworth, H., Godsell, J., Wong, C.Y., Saghiri, S. and Julien, D., 2015. Supply chain alignment for improved business performance: an empirical study. Supply Chain Management: An International Journal. 17(4) 419-437

[10] Christopher, M., 2012, January. Managing supply chain complexity: identifying the requisite skills. In Supply Chain Forum: An International Journal, 13(2) 4-9. Taylor \& Francis.

[11] New, S., 2010. The transparent supply chain. Harvard Business Review, 88(10)7682. 
[12] Lee, H.L., Padmanabhan, V. and Whang, S., 1997. Information distortion in a supply chain: The bullwhip effect. Management science, 43(4) 546-558.

[13] Pibernik R, Sucky E. Centralised and decentralised supply chain planning. International Journal of Integrated Supply Management. 2006 Jan 1;2(1-2) 6-27.

[14] Jonsson, P., Andersson, D., Godsell, J., Diefenbach, T., Clemmow, C., Towill, D. and Christopher, M., 2011. Enabling supply chain segmentation through demand profiling. International Journal of Physical Distribution \& Logistics Management 09600035

[15] Godsell, J., Bal, J. and Abramo, M., 2019. Rajesh Shankar Priya. Enhancing UK Manufacturing Productivity by enabling a Value Chain orientation, PhD thesis, University of Warwick. 